$11-2014$

\title{
Method for investigating nursing behaviors related to isolation care.
}

\author{
Elizabeth L. Beam \\ University of Nebraska Medical Center, ebeam@unmc.edu
}

Shawn G. Gibbs

University of Nebraska Medical Center

Angela L. Hewlett

University of Nebraska Medical Center, Department of Internal Medicine, Division of Infectious Diseases, alhewlett@unmc.edu

Peter C. Iwen

University of Nebraska Medical Center, piwen@unmc.edu

Suzanne L. Nuss

Nebraska Medicine, sInuss@nebraskamed.com

See next page for additional authors

Tell us how you used this information in this short survey.

Follow this and additional works at: https://digitalcommons.unmc.edu/con_articles

Part of the Nursing Commons

\section{Recommended Citation}

Beam, Elizabeth L.; Gibbs, Shawn G.; Hewlett, Angela L.; Iwen, Peter C.; Nuss, Suzanne L.; and Smith, Philip W., "Method for investigating nursing behaviors related to isolation care." (2014). Journal Articles: College of Nursing. 26.

https://digitalcommons.unmc.edu/con_articles/26

This Article is brought to you for free and open access by the College of Nursing at DigitalCommons@UNMC. It has been accepted for inclusion in Journal Articles: College of Nursing by an authorized administrator of DigitalCommons@UNMC.For more information, please contact digitalcommons@unmc.edu. 


\section{Authors}

Elizabeth L. Beam, Shawn G. Gibbs, Angela L. Hewlett, Peter C. Iwen, Suzanne L. Nuss, and Philip W. Smith

This article is available at DigitalCommons@UNMC: https://digitalcommons.unmc.edu/con_articles/26 
Accepted manuscript for *Beam, E. L., Gibbs, S. G., Hewlett, A. L., Iwen, P. C., Nuss, S. L., \& Smith, P. W. (2014). Method for investigating nursing behaviors related to isolation care. American Journal of Infection Control, 42, 1152-1156. https://doi.org/10.1016/i.ajic.2014.08.001

Title: A method for investigating nursing behaviors related to isolation care

Authors: *Elizabeth L. Beam, MSN, RN, University of Nebraska Medical Center (UNMC) College of Nursing; Shawn G. Gibbs, PhD, UNMC College of Public Health, Environmental, Agricultural, and Occupational Health; Angela L. Hewlett, MD, UNMC College of Medicine, Infectious Diseases; Peter C. Iwen, PhD, UNMC College of Medicine, Pathology/Microbiology; Suzanne L. Nuss, The Nebraska Medical Center, Director for Care Transitions and Nursing Outcomes; Philip W. Smith, MD, UNMC College of Medicine, Infectious Diseases

*Corresponding Author Information: Elizabeth L. Beam, MSN, RN, 985330 Nebraska Medical Center, Omaha, NE 68198-5330, W: 402-559-6547 E: ebeam@unmc.edu

Acknowledgements to: Stephen Smith for study technical support, Andrea Gaydess who acted as the standardized patient, Shelly Schwedhelm for donating use of some equipment and recruitment support, Kate Boulter for coordinating use of the Nebraska Biocontainment Patient Care Unit, and Dr. Eleanor G. Rogan for her guidance. 
Title: A method for investigating nursing behaviors related to isolation care

Abstract: Background: While an emphasis has been placed on protecting patients by improving healthcare worker compliance with infection control techniques, challenges associated with patient isolation do exist. To address this, a more consistent mechanism to evaluate specific clinical behaviors safely is needed. Methods: The research method described in this study used a high fidelity simulation using a live standardized patient recorded by small cameras. Immediately after the simulation experience, nurses were asked to view and comment on their performance. A demographic survey and a video recorded physical evaluation provided participant description. A questionnaire component one month after the simulation experience offered insight into the timing of behavior change in clinical practice. Results: Errors in behaviors related to donning and doffing equipment for isolation care were noted among the nurses in the study despite knowing they were being video recorded. This simulationbased approach to clinical behavior analysis provided rich data on patient care delivery. Conclusion: Standard educational techniques have not led to ideal compliance, and this study demonstrated the potential for using video feedback to enhance learning and to ultimately reduce behaviors which routinely increase the likelihood of disease transmission. This educational research method could be applied to many complicated clinical skills. 
Title: A method for investigating nursing behaviors related to isolation care 
Introduction:

Infection prevention continues to be an issue across the healthcare spectrum. A number of studies have been published looking at basic procedures such as hand hygiene, but methods have not been consistently applied between studies and the results are often not completely explained. ${ }^{1}$ Recent research approaches to hand hygiene have included qualitative data collection, ${ }^{2}$ a combination of videotaping and self-report, ${ }^{3}$ and performance improvement projects. ${ }^{4}$ Additional methods to evaluate infection prevention behavior are needed to both enhance continued learning and determine infection control compliance within active healthcare workers.

Personal protective equipment (PPE) use also remains an important component of healthcare worker safety and infection prevention. Surveys and epidemiological investigations have found PPE use to be suboptimal or inadequate. ${ }^{5,6}$ Some research studies have examined contamination after doffing multiple types of $\mathrm{PPE}^{7}$ and glove removal. ${ }^{8}$ These studies have noted the potential for contamination with these processes. Observational studies have commonly investigated PPE by examining the care of isolated patients, ${ }^{9}$ care given during resuscitation, ${ }^{10}$ and pediatric resuscitation using in situ simulation. ${ }^{11}$ All of the studies noted the need to improve performance related to the use of PPE. A study by Mawdsley, Garcia-Houchins, and Weber ${ }^{12}$ showed a surveillance program for contact precautions can lead to improvements to adherence to implementing precautions, but it did not report any behavioral observations at the bedside or infection control outcome data. While the challenges associated with patient isolation are noted in the literature, a more consistently applied mechanism to evaluate specific clinical behaviors safely is needed.

Simulation study designs need to be more consistent and robust to strengthen the evidence for use of the educational technique, and current study designs have not focused on the transfer of knowledge to clinical practice. ${ }^{13}$ The research method described in this study used Donald Schön's theory of reflective practice $^{14}$ in a high fidelity simulation using a live standardized patient recorded by small cameras. Immediately after the simulation experience, all study participants used retrospective verbal report techniques while viewing the patient care performance to describe the experience of the care processes. ${ }^{15}$ This study has the advantages of reducing the intimidation of having an evaluator in the presence of the subject and removing any guilt related to harming a real patient.

Methods:

This study evaluated the isolation behaviors of nurses for airborne and contact precautions in a simulated patient care setting at a Midwestern academic health science center. The hospital is a 627 acute care bed facility. The goal for enrollment was 20 to 30 staff nurses. This method of evaluation included a real hospital room and small High Definition (HD) digital cameras. The study built on previous work related to infection prevention. ${ }^{16}$

Following an expedited review by the Institutional Review Board, study participants were recruited by email. Due to system limitations for mass email, nursing managers were asked to forward the study invitation to their nurses. To improve recruitment, a flyer was later developed and posted in break rooms and nursing workspaces in the hospital. The nurses had to work at least 20 hours per week as a 
nurse in a direct patient care role to be included in the study. After consenting to participate in the study, each nurse was video recorded during a simulation experience. The nurses were assured prior to signing consent that all video would be maintained on encrypted drives and only be available to study personnel.

The nursing patient care scenario was similar to one used in our previous study. ${ }^{16}$ The scenario and simulation experience were intentionally simple to reduce the demonstration of errors which might arise from emergent care situations and to effectively test the methodology. The scenario involved a patient hospitalized to rule out tuberculosis. The patient had orders for airborne and contact precautions as well as continuous intravenous fluids. The care included an early shift head-to-toe assessment and a request for some pain medication. A computer workstation, essentially a laptop computer on a cart with a corded barcode wand, was a part of the simulation. For simulation purposes, there was no active patient to select in the electronic medical record and no active barcode on the armband to scan. Nurses were told to pretend as if they were using the computer workstation in their unit or practice area.

The simulated care experience used a live volunteer as the simulated patient and took place in a fully functional patient room at The Nebraska Medical Center in Omaha, Nebraska (Figure 1). One camera outside the room captured donning behaviors and the room exiting process. Two cameras were placed in the room strategically to capture nursing care at the bedside and doffing behaviors at the patient room door from two angles. The lightweight HD cameras were hung with simple clamps from the ceiling tile brackets. The simulated patient wore a hospital gown, a fake intravenous line taped to her arm, and a drainage bag under the bed linens for the infusion of medication and fluids. The pain medication the nurse gave was tap water in a syringe marked as a diluted 2 milligram dose of morphine sulfate. Isolation materials included typical signage for the facility and an isolation cart in the hallway outside the patient room containing gowns, gloves, masks, and eyewear. The gowns used in the study come in one size and were washable. The gowns were made available to the participants as they would normally come from medical materials. Gloves in all sizes were available on the cart. An N95 respirator was to be used in the simulation because of the physician orders in the scenario, isolation signage, and patient condition. There were both $\mathrm{N} 95$ respirators and standard procedure masks on the cart. Many styles of eyewear were available for use. Waste receptacles and linen hampers were available in the room as appropriate.

Within 10 minutes of completing the simulation experience, the nurses were asked to "think aloud" as they reviewed their video recording describing the rationales for their patient isolation behaviors. ${ }^{15}$ The nurses were cued on certain behaviors of interest including cleaning the computer workstations and use of the N95 respirator. The HD cameras recorded to Secure Digital or SD cards which were transferred to a computer or laptop for immediate viewing. After the video review was complete, the nurses were given the Centers for Disease Control and Prevention (CDC) Guidelines for the use of PPE ${ }^{17}$ to review and comment. The audio of the "think aloud" session and CDC Guideline review was recorded and later transcribed for analysis. Similar to our previous study, ${ }^{16}$ a scoring sheet was developed to evaluate the nursing behaviors for analysis. Video recordings taken in the hospital room were edited to view side-byside simultaneously. At least three reviewers scored each video recording of the nurse's performance 
individually, and then any discrepancies were discussed until consensus was reached on the scores for each component.

There were three more steps for the nurses to complete study participation. First, they were asked to complete a demographic survey on age, gender, race, education, years of experience, nursing practice, fatigue and blood borne pathogen exposure. Next, the nurses were asked to do some range of motion activities while being video recorded. This was to ensure that there were no physical limitations that might have impacted performance during donning and doffing activities. The movements specifically included the ability to reach the neck and waist areas as well as finger dexterity. The camera that was outside the patient room was used for this video recording. Finally, the nurse was asked for an email address and told that they would receive a follow up email at 1 month with a short 3 open-ended question survey about practice change after the simulation, the timing of practice change, and additional clinical challenges.

Results:

There were 24 nurses that consented and participated in the study. Three of the 24 participants were male. The age range was from 24 to 61 , with an average of 33 years old. $92 \%$ reported at least having a Bachelor of Science in Nursing. $46 \%$ of the nurses had over 5 years of clinical care experience. $42 \%$ had a previous experience with a personal blood borne pathogen exposure. The computer workstation for medication administration was a part of the patient care simulation that each nurse was told to use as they would in their patient care area. As a result, 18 brought the computer workstation in and out of the room, while 6 left it in the room.

Video scoring was divided into three major categories. The data is presented as a tally of individual behaviors in tables for 'quality of donning' (Table 1), 'in room activities' (Table 2), and 'quality of doffing' (Table 3). The "think aloud" and CDC Guideline review transcriptions were coded using qualitative description as described by Sandelowski. ${ }^{18}$ The 39 different codes were categorized into 'donning issues,' 'in room issues,' and 'doffing issues' in a similar fashion to the video scoring data.

Within donning quality (Table 1), poor compliance was noted with gowns, respirators, and eye protection. All nurses entered the room wearing a gown, but the gowns were rarely tied at the neck and the waist. One nurse talked about taking special care to untie knots in the gown and tie it snugly at the neck, while four others admitted to routinely just throwing the knot over their head. Eight nurses verbally noted routinely not tying the lower tie in practice. While all nurses in the study used the N95 mask, the number who sealed the mask was small, and fit checking was not done at all. One nurse commented, "And I have been fit tested, but I didn't do the actual mask, I mean... when I put it on." One male nurse did not recognize that his facial hair would impact the respirator seal. A female nurse commented on hairstyle factors impacting the mask seal. Two nurses only used one of the two straps of the $\mathrm{N} 95$ respirator during the simulation. When asked about the respirator's second strap, one nurse said "We have a TB room, but not until we get them...do we break out that equipment." Another comment indicated a knowledge deficit regarding airborne precautions saying, "And like I said, I didn't know, with TB, like it doesn't show on the sign that you need a mask...do you?" Eye protection was 
rarely used. In discussing the CDC guidelines, ${ }^{17}$ one nurse had never thought of administering an IV medication as a splash risk. Three nurses used the eyewear available on the isolation cart. Two of the nurses donned them correctly while the third one placed the eyewear on their head like a headband and adjusted it for use when needed during the patient care. Donning order was never done exactly as prescribed by the CDC guideline. ${ }^{17}$ One nurse commented, "I don't...to me I don't really think it matters when you're going in, I can obviously understand it more going out."

Regarding in room activities (Table 2), most nurses refrained from touching unprotected areas of their own bodies with the gloves and did not conduct unnecessary touching of surfaces in the room. In the simulation, most nurses completed the head to toe assessment before giving the medication, but one nurse noted infection control reasons for doing it differently by saying, "I guess my rationale here was assess for pain before I give the pain medications, use the computer while I haven't had any direct contact with the patient or any of the patient's belongings." Gaps in protection at the wrist between the gown and glove cuff as well as respirator adjustment did occur in the room, potentially reducing the participant's protection from fomites or aerosols. Gaps were more common in taller nurses, indicating the gowns were not large enough for some of them. Two nurses spoke specifically about the discomfort of the respirators. Another nurse spoke about adjusting the respirator in the room, and then changing gloves before returning to patient care. Items such as stethoscopes for patient care were consistently scored as creating an opportunity for exposure due to the lack of disinfection either before or after use. Comments about disinfecting the stethoscope focused on the earpieces and the bell, with little attention given to disinfecting the entire piece of equipment or transmission of germs up around the face when used.

Finally, regarding doffing activities (Table 3), the items used were consistently discarded properly, but many nurses did not perform slow and intentional removal of gowns or masks. The nurses did not often recognize the aerosolization issues related to rolling the gown, but one nurse said, "I'm trying to take this off like inside out...and then I roll it, but I roll it kind of towards me instead of away from me." Doffing order was also never done exactly as prescribed by the CDC guideline, ${ }^{17}$ but some nurses did properly sequence the items they chose to wear. For example, one nurse said "...start taking off my gloves first, keeping in mind that they're dirty on the outside...and then my gown keeping in mind that it too is dirty on the outside. And...my mask is last." Two nurses questioned taking the gloves off first. One of those nurses commented, “Okay, interesting...and I don't know why...usually gloves are the last thing I take off just 'cause, in case I touch anything else or something, you know, then it's like, I'm not doing it with my bare hands."

Decontamination of the computer workstation created multiple challenges for the nurses and further analysis and study is needed. Two nurses did not clean the equipment at all. Disinfection of equipment was done by nine of the nurses with bare hands. Four nurses reached into the clean isolation cart with dirty hands to get gloves for cleaning the computer workstation, while three donned new gloves before exiting the room. Disinfection focused on areas that the nurse or patient touched during the patient care scenario instead of all surfaces of the equipment. 
Upon review of the range of motion movement video recordings, only one participant displayed stiffness with large body motions and some lack of control with fine motor skills. In the simulation, this participant asked for help in tying the gown's lower tie and a research team member assisted. All other nurses performed the range of motion movements without difficulty.

The emailed one month follow up questionnaire was completed by 14 of the 24 participants. The first question asked about changes in clinical practice following the simulation experience. The most common term used was "order" in that nurses recognized there was a proper order and process for donning and doffing their PPE. Some other comments included thinking about transporting patients with isolation precautions and more frequently disinfecting laptop computers on carts used in patient care. One noted sharing their learning experience with coworkers. The second question asked when the changes in practice occurred if they were noted in the first question. Seven of the answers indicated an immediate change in practice. One participant noted within a couple of weeks, and another nurse thought that while the order concepts created change immediately some other behaviors changed over time as they thought more about the care of the isolation patient. The last question asked about additional clinical challenges in the care of patients in isolation. Three participants spoke of time challenges and demands of clinical care, and one of those three nurses mentioned the culture of the institution. Three nurses talked about cleaning items taken from room to room in the care of the patient and the quality of room or patient care spaces. Gowns were specifically noted by two respondents. One commented on gown size, while another spoke to knots when the gowns come back from the laundry.

Discussion:

A simulation-based approach to clinical behavior analysis in this study provided rich data on how patient care was delivered at the bedside. Investigating infection control processes specifically necessitated combining performance scoring and reflection in a new way. The study question needed to include both what is happening at the bedside and why it is happening. The idea for this combination of study techniques came from the literature. Whyte, Cormier, and Pickett-Hauber ${ }^{19}$ successfully used concurrent and retrospective verbal reports to evaluate prioritization and provision of care for congestive heart failure patients using simulation, but did not specifically score or evaluate certain clinical behaviors within the simulation. In our study the verbal reports were not collected concurrently, but instead as the video of the nurse's performance were reviewed. This allowed the nurse to operate in the simulation as they normally would to give patient care, but then step back and fully review their own performance with the benefit of hindsight.

The science of simulation in healthcare for education continues to evolve ${ }^{13}$ and randomized controlled trials using the technique are rare. ${ }^{20}$ While the research questions for this simulation research were specifically related to infection prevention behaviors in nurses, this reflective practice method could be applied to many clinical skills and other health professions. This amount of evaluation is most likely useful when the skill requires the delicate balance of self-protection from hazards and maintaining sterility. In this study, the simulated patient care scenario engaged the nurses to get into a normal nursing role, but the study was not without some limitations. Our work only evaluated washable gowns, 
when many healthcare facilities utilize disposable ones. An interactive electronic medical record for using the computer workstation to administer the pain medication would have added another layer of complexity and realism. Also, the sample size was small and included nurses from only one institution.

Similar to our previous study, ${ }^{16}$ the nurses demonstrated several errors in donning and doffing their PPE despite the fact they were knowingly video recorded. No nurses in the current study described specific behaviors caused by anxiety related to the filming. Our findings regarding individual PPE behaviors were similar to Watson, et al. ${ }^{11}$ and Mitchell, et al. ${ }^{9}$ In the study by Watson, et al., ${ }^{11}$ issues with tying of the gown and sealing the N95 respirator were noted, including strap placement. Eye protection use in the Watson, et al. ${ }^{11}$ study was $61 \%$ for pediatric resuscitation simulations, and the Mitchell, et al. ${ }^{9}$ noted $37 \%$ eye protection use in a multi-hospital observational study of healthcare workers caring for febrile respiratory illness patients. These rates are higher than the findings in this study, perhaps due to the Hawthorne effect. The simulation study ${ }^{11}$ used a mobile audio-visual cart, while the observational study ${ }^{9}$ used auditors.

The qualitative findings of this study describe a knowledge deficit among nurses in some specific areas regarding the use of PPE for infection prevention. The N95 respirator is a good example of the educational need. Nurses in the study were well versed in the need for fit testing the respirator and wearing the right size, but when applying it for use they did not routinely use proper strap placement or demonstrate the fit check before entering the room. Protective eyewear is another piece of equipment that was misunderstood. Nurses in the study did not understand its role in their self-protection, either in isolation settings or in typical patient care situations with a high risk of splash. Several clinical questions arose for the research team regarding the use of protective eyewear which have never been addressed in the nursing literature simply because nurses do not routinely wear safety eyewear in patient care, even when emptying drains, commodes, or working with other invasive lines. Gown and glove use also garnered multiple comments from the nurses. While some nurses explained errors due to misunderstanding, many described knowingly and repeatedly committing an error because of personal discomfort, perceived low risk, or lack of time.

As discussed earlier, Watson, et al. ${ }^{11}$ conducted a study of PPE adherence in pediatric resuscitation during the 2009 pandemic using high fidelity simulators, video recording, and anonymous surveys, but they did not conduct any type of interview or collect qualitative data from each participant. Our study used a very simple, predictable patient scenario in order to eliminate errors caused by the emergent nature of a patient condition such as resuscitation. Discrete cameras in a real hospital room also helped to increase the simulation's fidelity. Collecting video of range of motion movements provided new information about the physical limitations of our study participants and how this might impact PPE use.

Standard educational techniques have not led to ideal compliance, and we propose using video feedback to enhance learning and to ultimately reduce behaviors which routinely increase the likelihood of disease transmission. This educational research method could be applied to many complicated clinical skills. Behavior modeling and dialogue have been shown to be more effective in many types of safety training. ${ }^{21}$ Healthcare providers are rarely given the opportunity to see themselves perform their duties and to reflect on the quality of the care they provide. In our study, nurses who completed the 
one-month follow up questionnaire predominantly felt the simulation experience positively changed their clinical practice immediately. Integrating some features of this research study into educational delivery mechanisms on infection control practice may be helpful in creating lasting impressions for nurses providing care at the bedside. Future studies should include multiple simulation events to examine behavior change over time as well as the investigation of infection control behaviors in different types of healthcare providers both in the hospital and ambulatory settings. 
Figure 1. Hospital Room Simulation Layout

\section{Simulation Layout}

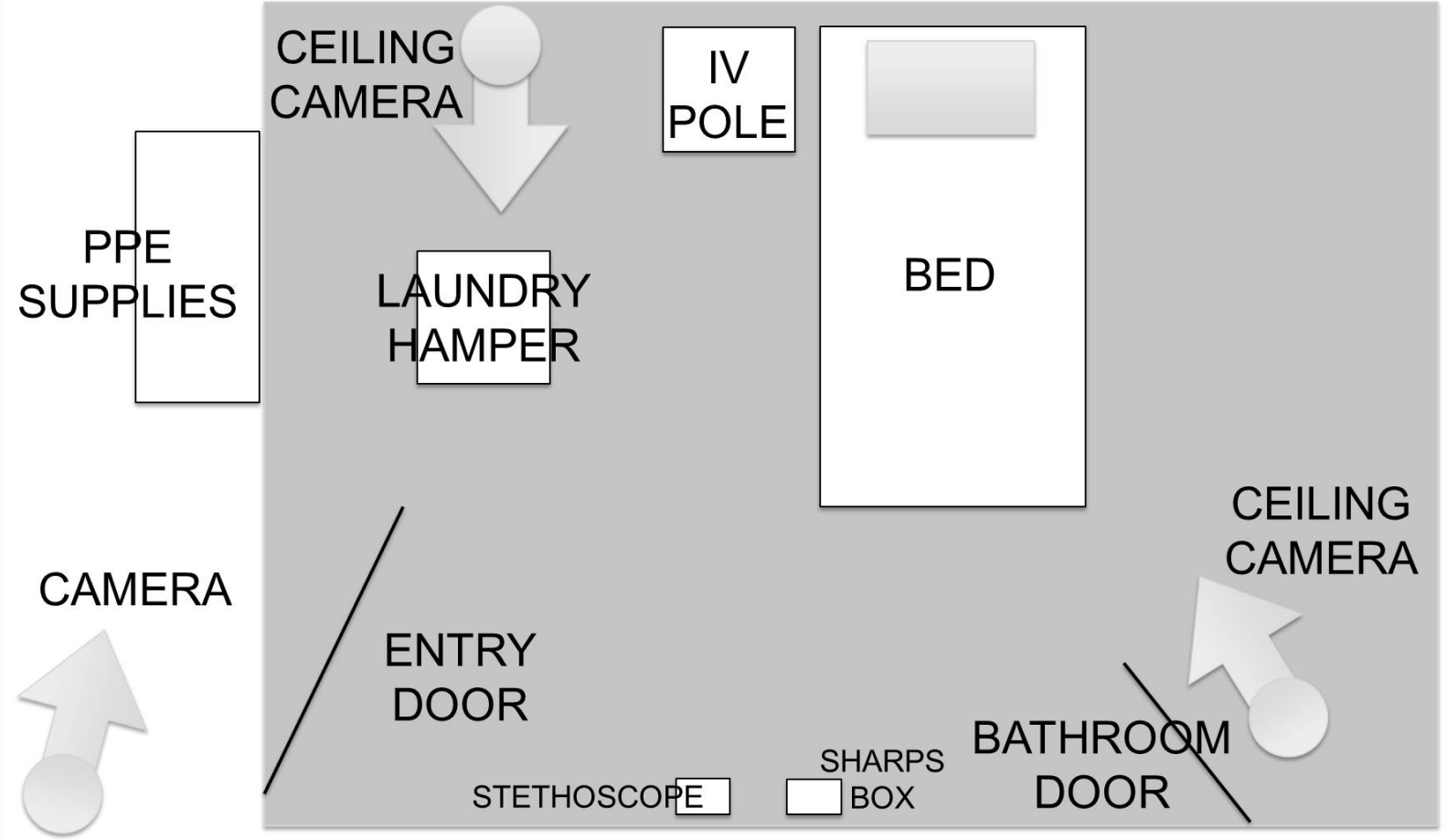


Table 1. Donning Quality Video Scoring Results, n=24 nurses

\begin{tabular}{lcc}
\hline \multicolumn{1}{c}{ Quality of Donning } & MET & $\begin{array}{c}\text { NOT } \\
\text { MET }\end{array}$ \\
\hline $\begin{array}{l}\text { 1) Perform hand washing } \\
\text { 2) Gown right side out }\end{array}$ & 21 & 3 \\
\hline 3) Tie gown at neck and waist & 6 & 14 \\
\hline 4) Ties done in bow (secure but easy to untie) & 8 & 16 \\
\hline 5) Don N95 Respirator & 24 & 0 \\
\hline 6) Seal N95 Respirator (fit snug to face and below & 10 & 14 \\
$\quad \begin{array}{c}\text { chin) } \\
\text { 7) Fit-check the N95 Respirator }\end{array}$ & 0 & 24 \\
\hline $\begin{array}{l}\text { 8) Respirator straps positioned correctly (placed } \\
\text { behind head and at base of neck) }\end{array}$ & 12 & 12 \\
$\begin{array}{l}\text { 9) Don eye protection } \\
\text { 10) Don gloves with gown cuffs under the glove } \\
\text { covering wrist of isolation gown }\end{array}$ & 2 & 22 \\
\hline
\end{tabular}


Table 2. In Room Video Scoring Results, n=24 nurses

\begin{tabular}{lcc}
\hline In Room Activities & Yes & No \\
\hline $\begin{array}{c}\text { 1) Touch their face or other non-protected areas } \\
\text { of body with gloves (If so, list \# of times) }\end{array}$ & 4 & 20 \\
$\begin{array}{l}\text { 2) Gap develops between gown cuff and glove } \\
\text { 3) Performed unnecessary/unwarranted touching } \\
\quad \text { of the environment }\end{array}$ & 3 & 15 \\
$\begin{array}{l}\text { 4) Adjust N95 Respirator (breaking the seal) or } \\
\text { other PPE }\end{array}$ & 9 & 15 \\
\hline $\begin{array}{c}\text { 5) Unprotected areas of body in contact with } \\
\text { potentially contaminated surfaces or } \\
\text { objects in room (example: stethoscope) }\end{array}$ & 22 & 2 \\
\hline
\end{tabular}


Table 3. Doffing Quality Video Scoring Results, $n=24$ nurses

\begin{tabular}{|c|c|c|}
\hline Quality of Doffing & MET & $\begin{array}{l}\text { NOT } \\
\text { MET }\end{array}$ \\
\hline 1) Remove gloves using glove-in-glove technique & 12 & 12 \\
\hline 2) Dispose of gloves properly & 21 & 3 \\
\hline 3) Remove eye protection without touching face & 3 & 0 \\
\hline $\begin{array}{l}\text { 4) Reusable eye protection placed in the } \\
\text { contaminated area }\end{array}$ & 0 & 3 \\
\hline $\begin{array}{l}\text { 5) Untie gown and remove by grasping gown at } \\
\text { the shoulders }\end{array}$ & 5 & 19 \\
\hline $\begin{array}{l}\text { 6) Remove gown by slowly pulling it down, rolling } \\
\text { inside out to form a bundle and keeping } \\
\text { gown close to body }\end{array}$ & 6 & 18 \\
\hline 7) Open laundry hamper using foot pedal & 7 & 17 \\
\hline 8) Place entire gown into laundry hamper & 24 & 0 \\
\hline $\begin{array}{l}\text { 9) Remove respirator by grasping elastics at the } \\
\text { back of the head and moving them } \\
\text { forward }\end{array}$ & 5 & 19 \\
\hline 10) Dispose of respirator in garbage & 24 & 0 \\
\hline $\begin{array}{l}\text { 11) Use of hand sanitizer available before } \\
\text { touching door to exit }\end{array}$ & 5 & 19 \\
\hline 12) Perform hand washing & 20 & 4 \\
\hline
\end{tabular}


References:

1. Erasmus, V., Daha, T. J., Brug, H., Richardus, J. H., Behrendt, M. D., Vos, M. C., et al. Systematic review of studies on compliance with hand hygiene guidelines in hospital care. Infect Control Hosp Epidemiol, 2010; 31: 283-294.

2. Erasmus V, Brouwer W, van Beeck E F, Oenema A, Daha T J, Richardus J H, Vos M C, Brug J. A qualitative exploration of reasons for poor hand hygiene among hospital workers: Lack of positive role models and of convincing evidence that hand hygiene prevents cross-infection. Infect Control Hosp Epidemiol, 2009; 30: 415-419.

3. Hassan Z M, Pryor E R, Autrey P S, Turner J G. Hand hygiene compliance and nurse-patient ratio using videotaping and self report. Infect Dis Clin Pract, 2009; 17: 243-247.

4. Armellino D, Trivedi M, Law I, Singh N, Schilling M E, Hussain E, et al. Replicating changes in hand hygiene in a surgical intensive care unit with remote video auditing and feedback. Am J of Infect Control, 2013; 41:925-927.

5. Daugherty E L, Perl T M, Needham D M, Rubinson L, Bilderback A, Rand C S. The use of personal protective equipment for control of influenza among critical care clinicians: A survey study. Crit Care Med, 2009; 37:1210-1216.

6. Jaeger J L, Patel M, Dharan N, Hancock K, Meites E, Mattson C, et al. Transmission of 2009 pandemic influenza A (H1N1) virus among healthcare personnel-Southern California, 2009. Infect Control Hosp Epidemiol, 2011; 32:1149-1157.

7. Casanova L, Alfano-Sobsey E, Rutala W A, Weber D J, Sobsey M. Virus transfer from personal protective equipment to healthcare employees' skin and clothing. Emerg Infect Dis, 2008; 14:1291-1293.

8. Lai J Y F, Guo Y P, Or P P L, Li Y. (2011). Comparison of hand contamination rates and environmental contamination levels between two different glove removal methods and distances. Am J of Infect Control, 2011; 39: 104-111.

9. Mitchell R, Roth V, Gravel D, Astrakianakis G, Bryce E, Forgie S, et al. Are health care workers protected? An observational study of selection and removal of personal protective equipment in Canadian acute care hospitals. Am J of Infect Control, 2013; 41: 240-244.

10. Chiang W, Wang H, Chen S, Chen L, Yao Y, Wu G, et al. Lack of compliance with basic infection control measures during cardiopulmonary resuscitation: Are we ready for another pandemic? Resuscitation, 2008; 77:356-362.

11. Watson C M, Duval-Arnould J M, McCrory M C, Froz S, Connors C, Perl T M, Hunt E A. Simulated pediatric resuscitation use for personal protective equipment adherence measurement and training during the 2009 influenza (H1N1) pandemic. Jt Comm J Qual Patient Saf, 2011; 37: 515523.

12. Mawdsley E L, Garcia-Houchins S, Weber S G. Back to basics: Four years of sustained improvement in implementation of contact precautions at a university hospital. Jt Comm J Qual Patient Saf, 2010; 36: 418-423.

13. Nestel, D., Groom, J., Eikeland-Husebø, S., O’Donnell, J. M. (2011). Simulation for learning and teaching procedural skills: The state of the science. Simulation in Healthcare 6, S10-S13. 
14. Schön D A. The Reflective Practitioner: How Professionals Think in Action. Basic Books: USA, 1983.

15. Ericsson K A, Simon H A. Protocol Analysis: Verbal Reports as Data (revised edition). MIT Press: Cambridge, 1993.

16. Beam E, Gibbs S, Boulter K, Beckerdite M, Smith P. A method for evaluating personal protective equipment technique by healthcare workers. Am J of Infect Control, 2011; 39:415-420.

17. Centers for Disease Control and Prevention. Guideline for Isolation Precautions: Preventing Transmission of Infectious Agents in Healthcare Settings 2007. Available from http://www.cdc.gov/hicpac/2007ip/2007isolationprecautions.html. Accessed May 17, 2014.

18. Sandelowski M. Focus on research methods: Whatever happened to qualitative description? Res Nurs Health, 2000; 23: 334-340.

19. Whyte J, Cormier E, Pickett-Hauber R. Cognitions associated with nurse performance: A comparison of concurrent and retrospective verbal reports of nurse performance in a simulated task. Int J Nurs Stud, 2010; 47: 446-451.

20. Jansson M M, Ala-Kokko T I, Ohtonen P P, Meriläinen M H, Syrjälä H P, Kyngäs H A. Human patient simulation education in the nursing management of patients requiring mechanical ventilation: A randomized controlled trial. Am J of Infect Control, 2014; 42: 271-276.

21. Burke M J, Sarpy S A, Smith-Crowe K, Chan-Serafin S, Salvador R O, Islam G. Relative effectiveness of worker safety and health training methods. Am J of Public Health, 2006; 96: 315-324. 